\title{
Perception of Regular Physical Activities and Factors Affecting Physical Activities Among Adult Government Office Worker in Adama Town, Ethiopia: Qualitative Study
}

\author{
Ebrahim Mohammed ${ }^{1}$, Mirgissa Kaba ${ }^{2}$ \\ ${ }^{1}$ Department of Public Health, Adama Hospital Medical College, Adama, Ethiopia \\ ${ }^{2}$ Department of Prventive Medicine, School of Public Health, Addis Ababa University, Addis Ababa, Ethiopia
}

Email address:

ebrahim.m805@gmail.com (E. Mohammed), mirgissk@yahoo.com (M. Kaba)

\section{To cite this article:}

Ebrahim Mohammed, Mirgissa Kaba. Perception of Regular Physical Activities and Factors Affecting Physical Activities Among Adult Government Office Worker in Adama Town, Ethiopia: Qualitative Study. American Journal of Health Research. Vol. 9, No. 5, 2021, pp. 190-197. doi: 10.11648/j.ajhr.20210905.17

Received: August 21, 2021; Accepted: September 1, 2021; Published: September 14, 2021

\begin{abstract}
Introduction: Physical activity has been traditionally defined as any bodily movement produced by contraction of skeletal muscle that substantially increases energy expenditure, although the intensity and duration can vary substantially. Physical activities prevent non communicable diseases. Objectives: To assess perception of regular physical activities and factors affecting physical activities among adult government office worker in Adama town, Oromia Regional State, Ethiopia, 2020. Methods: Phenomenological study design was employed. 10 Government office workers form four government offices and 1 Key informant from government office and 9 Physical exercise trainer from sport (Gyms) training center were interview using in-depth interview techniques. The sample selected purposefully and randomly. Questionnaires were prepared and modified using WHO Global Physical Activity Questionnaire (GPAQ) analysis Guide in English and then translated into two local languages (Amharic and Afan Oromo). Audio record was used and recoded the the interview of 20 sample populations. Data was reduced using the language the interviewee used and then translated into English. Data imported into Open code 4.02 softwares and categorized into summaries. Socio-demographic data were entered into SPSS version 21. Thematic area were identified and analyzed based on the themes. Result: a total 20 study participants (10 Government office worker and 10 Key Informant) were interviewed. All participants have good perception of physical activities. 7 of workers have moderately physical active (fulfill globally recommended physical activity rate) with 150 minutes of physical activity performance per week. The rest 3 workers have insufficient physical activities which is less than 150 minutes of physical activity per week. Factor like laziness, overloaded by office work, lack of self-confidence in doing physical activity, lack of awareness about physical activity, place factor, poor time management, lack of communication and economic status of workers were found as behaviors or factors affecting doing of physical activities among government office workers. Conclusion and recommendations: there is high number of physical activity insufficiency among workers and there are large numbers of factors that affect physical activity doing of workers. Therefore, the government should work on these factors to make worker healthy and productive.
\end{abstract}

Keywords: Physical Activity, Government Workers, Adult

\section{Introduction}

Physical activity has been traditionally defined as any bodily movement produced by contraction of skeletal muscle that substantially increases energy expenditure, although the intensity and duration can vary substantially [1]. Physical activity can be categorized into five. They are: Leisure-time physical activity (sports) for recreational purposes, condition and competition, Leisure-time physical activity such as gardening and household, Physical active transportation and commuting, Physical activity as a scheduled school subject or as a paid exercise during work-time and Non-scheduled physical activity as seen in kindergarten or school, or in a 
physical active job [2].

Regular physical activity can reduce the risk factors associated with morbidity and mortality among older adults. Being physically active can alter the course of many diseases that are prevalent in the population [3].

Despite such recommendations, many adults, especially middle-aged and elderly individuals, prefer to remain sedentary. Research conducted by the Center for Disease Control and Prevention, United States, in 1996 revealed that more than $60 \%$ of the adult population did not participate in physical activity and $25 \%$ was sedentary [4] Similarly, a study from Hong Kong reported that one-fifth of the registered deaths among people aged $\geq 35$ years in the country were associated with low levels of physical activity [5].

In quantitative study conducted in Malaysia in 2011, most middle age population do not participate in physical activities reasoning out that 'not enough time', 'no one to exercise with', and 'lack of facilities', were 'too tired', 'already active enough due to daily life activities situation', 'do not know how to do it', and 'too lazy' [6].

In another quantitative study conducted in southern Brazil, in 2010, 29.7 percent of elderly populations were physically active for 150 minutes and perceived that the existence of public lighting at night, the sensation of safety during the day, the existence of sidewalks, and of green areas, and the presence of pedestrian tracks are environmental factors that can affect physical activities of elderly patients [7].

Another mixed study have been conducted in Ghana in 2014; study participants said time constraints and personal safety were common barriers to participate in regular physical activities 8]. In this study one participant said, "It takes a lot of time in the day and we don't have that time... I try to do exercises that are safe for me, for my age, but I don't always know what I can and cannot do..." Multiple women mentioned the importance of safety when exercising, reflecting that they desired more knowledge of safe exercises, ageappropriate exercise programs, and healthy eating habits [8].

In one of qualitative study conducted among university students in Malyasia, Majority of the respondents responded to question "what comes to your mind when you think of physical activity? Exercises are the first things come tomind when think about physical activity. One of them said:

"Of course the first thing is about healthy. When people do exercise it is called physical activity. Even dancing or walking, that would be considered as physical activity." (Male, 22years old, Malay).

In population based quantitative study conducted in Dire Dawa, 34.1\% reported no physical activity that lasted for at least 10-min continuously in any of the three physical activity domains. Whereas, out of the $65.9 \%$ who reported doing physical activity for at least 10-min continuously, 59.0\% reported moderate-in-tensity physical activity at workplaces and $53.9 \%$ reported activity during travel to and from places. Approximately $22 \%$ of the adults did vigorous-intensity activity for 75-min or more per week. The proportion of men who did vigorous-intensity activity were more than three-fold higher compared to women [9]. In another study conducted in eastern part of Ethiopia, Harar Twon, male adults were more likely to practice physical activity than females [10].

In qualitative study conducted among older peoples in Perth, Western Australia, most of the study participants belief that physical exercise is essential for promoting health. Some of the study participants said

"Dot: You breathe better. It keeps you trim and certainly gets your bowels moving.

The blood circulates better and that helps your skin.

Ruth: It keeps your muscles toned up and your body fit. Walking keeps you going as you get older. It would just make you feel better."

Two of the study participants reported that pain is the most common barrier to engage in physical activities

"Jan: Oh pain most of the time. It's actually a spur underneath my foot and on the back of my foot. It's a dull ache most of the time.

Max: I have got a crook back, which is my own fault, so I got to learn to live with it." [11]

In another qualitative study conducted in two different municipalities in Sweden among older people and professionals at four assisted living facilities, all study participants were asked the same question "If I say physical activity, what does the concept mean to you?" and they answered in the following manner. One of them said

"It's moving physically and feeling good."

Another participant said

"Yes, physical activity is just being, so that means everything I do here."

Again another participant said

"All movements you're able to do I think is physical activity. It's not just standing and walking, I think. Physical activity can be that I can make my head move, and I can use it if it is the only part of my whole body I can move. I'm thinking of the whole person. I mean, you're not thinking that now we're doing physical activity and now we're doing something else - it comes into everything. What am I able to do and what part of my body am I able to use and do I WANT to use it?"

And one of the study participant said

"I think it's all activity involving a physical movement. I mean, like, when you're using your body in some way. When you're walking and moving around, and when you massage someone's hands to get the circulation going in one's fingers." [12].

In one of the study conducted in Brazil, on the total population, almost about $40 \%$ of the study participants were inactive and do fulfill the criteria of moderate intensity of physical activity or do not fulfill the criteria of GRPAR (Globally Recommended Physical Activity Rate) which is 150 minutes of physical activity within a week 13]. In another study conducted in the parents of students from Amelia Rodrigues Public School, located in Monte Gordo, district of the town of Camaçari, state of Bahia, Brazil, based on IPAQ classification, it was observed that $42.9 \%$ of the individuals in the LSEL group were classified as insufficiently active [14]. In another population level study in 
Mexico, physical inactivity among study population is $19.4 \%$ based on WHO GRPAR [15].

Study conducted among older female African - American, The motivations included perceived health benefits of physical activity, social support, and enjoyment associated with engagement in physical activity. Prominent barriers included time and physical limitations, peer pressure and family responsibilities, and weather and poor neighborhood conditions [16].

In one of qualitative study conducted in Australia among older people current and future context or need of physical activity was studies and one the participant said;

"Well, I gave up my tennis and my horse riding. But I kept up with aerobics. Then when I gave up the aerobics I took up walking and yoga. So the velocity has lessen just to suit my age and my body ... I've reduced it even more now and it's at a point now that I should gear up to do more" [11].

That means he want to keep aerobics and add walking and yoga.

From the above literature we understand peoples may perceive physical exercise in different ways. This will help to analyses perception of adults toward physical exercise.

One the study conducted in Dire Dawa, eastern part of Ethiopia shows that there is more than 30\% physically inactive population the study was quantitative and conducted on the general population. Ethiopian government and Addis Ababa city administration are working to create awareness of regular physical activities and exercise among citizens. But as to my knowledge, there is no information that shows the perception of regular physical exercise among government workers office. This study will explore the perception of regular physical activities among government workers in Adama town and help policy makers and cities health administration in establishing the way of creating awareness and bringing behavioral change in performing regular physical activities to promote health.

\section{Methods and Materials}

\subsection{Study area and Period}

The study was conducted in Adama town governmental institution, Oromia Regional State, Ethiopia, in, March 2020. Adama Town is located at about $100 \mathrm{Km}$ South-East of Addis Ababa in the great rift valley of East Africa. Under Adama town administrative there are 30 governmental offices providing public service for the residents. Adama Town is one of the big cities in Ethiopia with an area of 13000 square $\mathrm{m}^{2}$ and has a total population more than 337,556 (Census 11 years ago). In Adama town, there are a large number of workers working in governmental institutions and there are a large number of private institution workers. The study was conducted from February 25 to March 20, 2020.

\subsection{Study Design}

Phenomenological study design was employed among government office workers working in the governmental institutions in Adama town from February 25- March 15/ 2020.

\subsection{Source and Study Population}

\subsubsection{Source Population}

All Employees found in Adama town in governmental offices and trainer of physical activities.

\subsubsection{Study Population}

The study populations included all workers working in Adama town selected governmental organizations and trainer of physical activities.

\subsubsection{Inclusion Criteria}

All workers working in Adama town governmental organizations and trainer of physical activities at the time of study period will be included in this study.

\subsubsection{Exclusion Criteria}

Non-governmental organizations Workers, governmental organizations workers who are on annual leave, who newly joined the Adama town in the last six months, Workers who are critically ill and cannot participate in in-depth interview will be excluded and Health care professionals will be excluded.

\subsection{Sample Size Determination and Sampling Procedure}

Purposeful sampling was employed to select four governmental institutions and 9 gyms (raining centers) and Purposeful and random sampling of 10 study participants, two or three from each institution was selected and in depth interview and $10 \mathrm{KII}$ was conducted. Four government office was selected purposefully.

\subsection{Data Collection Procedures}

WHO Global Physical Activity Questionnaire (GPAQ) Analysis Guide is used to prepare questionnaires. Semi structured questionnaires for Socio-demographic part and unstructured questionnaires were prepared and used to collect data from government office employee and key informants by in depth interview. Questionnaires were prepared in English and translated into two local common languages (Amharic and Afan Oromo) by Bsc holder of language. The translated questionnaire was re-translated back to English by Language teachers working in another preparatory school in Adama to check its consistency. Interview was by investigator at workers office and in training centers. Sony audio recorder was used to record the voice of respondents.

\subsection{Data Quality Assurance}

Data was collected by researched. The investigator check for saturation after each interview. Those interviews found missing in addressing important responses was discarded and another interview was conducted with another participant.

\subsection{Data Processing and Analysis}

Frequency and distribution for socio-demographic data was analyzed using SPSS version 21 and displayed using 
tables. Data was transcribed; Open code 4.02 software was used to identify themes. Key themes was identified after initial review of the text. The data was organized into key themes. Data from each group of respondents was analyzed before they were combined into a summative review.

\subsection{Ethical Considerations}

Letter from AAU was sent to concerned officials and permission was secured. All Selected institution in Adama town was communicated before the start of the study. All the study participants were informed about the purpose of the study and verbal consent of all study subjects was obtained before data collection. Participants was informed that they have full right to discontinue or refuse to participate in the study or to be interviewed. To ensure confidentiality, the name of the interviewee was not described in the interview instead was numbered. The interview was made in a place where it was conducive to study participants in their institution compound. Each respondent was assured that the information provided by them will be kept confidential and used only for the purpose of research. Moreover, the study participants will be informed that there is no risk or harm that will be anticipated from participation in the study.

\section{Result}

\subsection{Socio-demographic Characteristics of Study Participants}

A total of 10 government workers and 10 key informants purposefully (trainers of physical activities) selected respondents were interviewed in in-depth interview. The mean age of government workers was 40.6 years $( \pm \mathrm{SD}=8.87)$ and the median age of Key informants is 32 years with IQR of 27.75-37.25, More than half of government workers are at below or equal to 40 years and $9(90 \%)$ of KI are below 40 years age. More than three fourth $8(80 \%)$ of the government workers were male and more than two third 7 (70\%) were Oromo and all KI are male. Regarding ethnic nature of the government workers $7(70 \%)$ and KI $6(60 \%)$ are Oromo, Orthodox and Muslims accounts for $4(40 \%)$ and $5(50 \%)$ for Government workers and KIs respectively. All of the government workers were graduated with the first degree and $4(40 \%)$ and KIs are at secondary level and degree graduate. The majority of the government workers $9(90 \%)$ married and live together and $60 \%$ of KIs married. Half $5(50 \%)$ of government workers are law experts, earn monthly income of 10,000 Eth. Birr and 4 (40\%) of the government workers are from Adama town finance and economy cooperation office. See table 1.

Table 1. Socio-demographic characteristics of study participants.

\begin{tabular}{|c|c|c|c|c|}
\hline \multirow{2}{*}{ Variables } & \multicolumn{2}{|c|}{ Gov. Workers } & \multicolumn{2}{|c|}{ Key Informants } \\
\hline & Frequency & Percent & Frequency & Percent \\
\hline \multicolumn{5}{|l|}{ Age Category } \\
\hline$<=40$ years & 6 & 60 & 9 & 90 \\
\hline$>40$ years & 4 & 40 & 1 & 10 \\
\hline \multicolumn{5}{|l|}{ Sex } \\
\hline Female & 2 & 20.0 & 0 & 0 \\
\hline Male & 8 & 80.0 & 10 & 100 \\
\hline Amhara & 3 & 30.0 & & \\
\hline Oromo & 7 & 70.0 & 6 & 60 \\
\hline Siltie/Gurage & & & 3 & 30 \\
\hline Hadiya & & & 1 & 10 \\
\hline \multicolumn{5}{|l|}{ Religion } \\
\hline Orthodox & 4 & 40.0 & 1 & 10 \\
\hline Muslim & 4 & 40.0 & 5 & 50 \\
\hline 9-12 (Secondary) & & & 4 & 40 \\
\hline Certificate/Diploma & & & 2 & 20 \\
\hline 1st degree & 10 & 100.0 & 4 & 40 \\
\hline \multicolumn{5}{|l|}{ Marriage } \\
\hline Not Married & & & 4 & 40 \\
\hline Married & 9 & 90.0 & 6 & 60 \\
\hline Divorced & 1 & 10.0 & & \\
\hline \multicolumn{5}{|l|}{ Profession } \\
\hline Accountant & 4 & 40 & 1 & 10 \\
\hline law expert & 5 & 50 & & \\
\hline Purchaser & 1 & 10 & & \\
\hline Trainers & & & 9 & 90 \\
\hline \multicolumn{5}{|l|}{ Family monthly income Category } \\
\hline$<=10,000$ birr & 5 & 50.0 & 6 & 60 \\
\hline$>10,000$ birr & 5 & 50.0 & 4 & 40 \\
\hline Adama municipal office & 3 & 30.0 & & \\
\hline
\end{tabular}




\begin{tabular}{llll}
\hline \multirow{2}{*}{ Variables } & Gov. Workers & \multicolumn{2}{c}{ Key Informants } \\
\cline { 2 - 4 } & Frequency & Percent & Frequency \\
\hline East shawa zone Finanace and economic cooperation & 2 & 20.0 & 1 \\
Adama town income and tax revenue & 1 & 10.0 & 10 \\
Gym (Training Center) & & & 9 \\
\hline
\end{tabular}

In this research four themes generated regarding the regular physical activities of government office workers in Adama town; 1). Perception of physical activities 2). Status of workers physical activities 3). Future willing of Physical Activities and 4). Barriers or factors affecting physical activities.

\subsection{Perception of Physical Activities}

At the time of in-depth interview, government workers were assessed how they perceive physical activities and they describe physical activities as follows;

" Physical activity is doing different types of sport activities in a regular ways (R1), physical activity mean it is health ( $R 2, R 8)$, ways of preventing diseases ( $R 3)$, sporting and working (R4), Situation of working peacefully (R5), working, walking and running (R6, R7 and R9), running, jumping rope and participating in other sport activities (R10).”

Most of trainers have similar perception and said that physical activity means;

"activities used to have good physical fitness, appropriate physical appearance and body building (R1), the way a person keeps himself from unnecessary things keep him healthy and relax his body and mind (R2), activities that used to keep our health (R3, R4), any activity that any person can do to be health and good physical appearance (5), activities important for human to keep his bodies strong (R6), activities used to keep health (R7), activities that contain not less than 7 Physical activities which are used to have good and strong physical appearances (R8), activities that are used to have good physical fitness, prevent diseases and made us healthy and brilliant and effective in our life (R9), activities of body that cannot static at one place (R10)."

Participants of each training center were identified by to check whether government worker participate in higher number or not compared to any other occupations. Almost all of trainers confirm that the number of government worker participating in sport training center or gyms is very small compared to others.

"Most of the trainees are students and traders; numbers of Government workers are very low (R1, R2), A large number of trainees are students and other nongovernmental workers. Most of the government workers do not came to training centers (R4), the number of government workers is too small (R5), Most of the trainees are children and youths, private worker/traders/ but government workers do not come to gym most of the time (R6, R7), Most of trainees are children and youth and other non-governmental employee, some of governmental employees starts to do physical exercise but most governmental employees do not come to do physical exercise (R8), The number of Government workers who come to training centers and gym are very small (R9), Most of trainees are youth; the number of government workers is small compared to others (R10)."

\subsection{Status/Level of Workers Physical Activities}

We measured the status of workers' physical activities using global recommended physical activities accumulation rate. The recommended global accumulation rate was calculated based the frequency and duration of their physical activities done in a week. Respondent (1, 3 and 6) some of the workers do not fulfill the total physical activities duration of 150 minutes per a week. That means they do not achieve globally recommended accumulation rate and they are in physical activity insufficiency.

"I walk 20 minutes per day for 7 days (R1), I walk for 30 to 40 minutes per day for 3 days per week (R3) and another respondent run for 30 minutes per day for 2 days per week (R6)."

The rest the study respondents (R2, 4, 5, 7, 8, 9, and 10) seven of workers achieved their global recommended accumulation rate that mean they do physical activities more than 150 minutes per week.

\subsection{Future willing}

From the total respondents (workers), only two (R1 and R2) showed need to go to gym and to do physical exercise other respondents do not need to go to gym and said

“... want to increase walking time and add pushup (R3), $I$ 'm interested in football playing and running (R5), if the environment is suitable, I want to play ground tennis and run (R7), I want to play football in my free time if playing place is appropriate (R8), Now I want to play football if it is possible and get appropriate time and I want to participate in programs prepared for mass sport (R9), I want to run and jump rope (R10) and I am interested in football playing and I want to use gyms but it is costly and I cannot afford it (R6)."

\subsection{Barriers or Factors Affecting Physical Activities}

There are many factors that can affect or influence the workers to do or not to do physical activities. This study shows that what motivates or encourage or discourage worker to do physical activities. Some the workers are motivated and encouraged by family and/or friends

"My wife encourages me to do physical activities (R1), My brother encourage me to participate in physical exercise (R2), my family and friends encourage me to do physical exercise (R3), my son and work situation encourage me (R5), my health situation and my family and friends 
encourage me to do physical exercise (R6)."

Others are motivated and encouraged by mass media programs, need of having good physical appearance and prevention of diseases

"Presence of physical activities programs in mass media motivate me (R7), Need of having good physical appearance and being alert in my work after physical exercise motivates me (R8), Participation of my friends in physical activities due diabetes motivates me (R9) and I motivated to do physical exercise by looking at those who are obese and need to reduce their weight. My family and friends motivate me to do physical exercise (R10)."

Most of study respondents said that nothing discourage them to do physical exercise but two workers (R 7 and 9) discouraged by some factors

"Becoming overloaded by my office work hinders me from doing physical exercise ( $R 7$ and $R 9)$ )"

Another factor that may affect workers physical activities may be place factor where workers can do physical activities.

"No appropriate place and situation for doing regular physical activities in our area (R1) and There is no place to make, no walking road side place (R2)."

Suggestion that may help workers aware and engage to physical exercise have been given to government (their office) by worker. Some the suggestion given by workers are as follows:

"Our office should facilitate physical exercise at the time of tea break and it should prepare gyms in our institution so that workers can easily get access and do physical exercise (R1, 3, 4), Government or our office should prepare place for physical exercise so that workers can come early and do physical exercise before they start and after they finish their work in office compound (R2, 7, 8 and 9), Our organization should facilitate the place and gym materials for physical exercise so that workers can do physical exercise and keep their health (R5) and Our organization should establish sport team or club so that we can participate and contribute to the club (R6)."

The main reason why government workers do not go gyms and training centers to do physical activities were assessed by interviewing the trainer of gyms and training centers. The trainers described the reasons as follows;

"The reason may be indolence (laziness), Economic status and distance of place for gyms and training centers (R1), The reason may be becoming overloaded by work, no time plan for their life (R2), The reason may be; 1) they think that the time may not appropriate for them. 2) They do not have enough knowledge about Physical activities (R4), they have low awareness about physical exercise (R5), our training center lacks shower room which make them discomfort (R6), The reason for not coming to our gym for most government workers is 1) losing self-confidence (believing that they cannot do physical exercise by this age) 2) Economic problem; fees for gym 3) attitude problem (not believing and accepting physical exercise as part of their life) (R8), the reason is that they do not have good attitude toward the trainers (R9), The reason for not come to our training center can be 1) Not having interest 2) lack of communication and awareness 3) distance of training center from their home (R10)."

\section{Discussion}

The result of this study shows that government workers perceives physical activities as activities that is used to keep body strong, used to be healthy and to promote health. The key informants described in the same way somewhat deeper than the government workers. The result of this study similar with studies conducted in Ghana [8], in Canada 2004 8], again similar with another qualitative study conducted among university students in Malyasia [17] and again similar with In another qualitative study conducted in two different municipalities in Sweden [12]. The similarity may be due to the fact that worker can search and read about the physical activities.

The levels of physical activity of the workers have been assessed using WHO GRPAR. In this study, about $30 \%$ of workers have physical activity of less than 150 minutes per week, which means $30 \%$ of workers have insufficient physical activity but the key informant are $100 \%$ achieved GRPAR and vigorously physically active. The result of this study inconsistent with the study conducted in Brazil. The inconsistency could be due difference in study population, study setting and economic status of the study participants and geographic locations [13]. Physical inactivity $30 \%$ of this study is very high compared to another study conducted in Mexico which was $19.4 \%$. The discrepancy may be due difference in study population, study setting and economic status of the study participants [15]. And again, the result of this study is almost similar with the study conducted in Dire Dawa, eastern part of Ethiopia. Even thought the study design is different, the result is similar. The similarity may be due to that people in Adama and Dire Dawa may share some life experience in their life situation and geographic and same climate (hot).

The result of this study shows that workers in need to participate in to regular physical activities. Keeping in mind the factors that may affect their need and the workers said that they want to go gyms, keeping up their activities that they are doing and want adding new types of activities. The result of this study is similar with the study conducted Australia. Even though, the type physical activities are not similar the idea of keeping up activities and need of adding another type of activity is similar. Similarity may be due to need to be health and strong by doing physical activities [16].

In this study, different factors have investigated as factors that affect physical activities of workers. Some of the factors are Need of having good physical appearance, prevention of diseases like diabetes, reduction of weight and family and friend support as motivators. Being overloaded by work (tiredness) as discouraging factor and facility factors like not safeness, distance, lack of motivation due to lack of aware, economic status, lack of transportation and etc are factors that affect physical activity of workers. The result of this study is 
similar with the study conducted in Malaysia [6] and America [16]. The similarity may due to the fact that all factors described can happen anywhere in any person and place factors are common in developing counties like Ethiopia and benefits of physical activity is almost similar everywhere.

In this study, I tried to see the number of government worker doing physical activities in gyms. Almost all KI said that there is very small number of government office worker come to Gyms or training centers by describing the reasons. I can find to triangulate this to others.

Both workers and key informants give suggestion regarding of engagement of workers into physical activities. The workers claim absence of place, distance of gyms and inability to pay for gym as a major reason for not to do physical activities. Therefore, they give suggestion that the government should prepare gyms in each organization and facilitate mass physical activities. But key informant believe that the main reasons for not doing physical activities as factors like laziness of workers, distance of gyms from residential area, lack of awareness among workers, not having interest, not having good attitude toward trainers and lack of communication. Key informants give suggestions that all these factors can get solution by government. Therefore, government should facilitate and establish gyms in every organization facilitate and make physical activity working place safe and suitable in residential area and create awareness about physical activities and its benefits regarding keeping the workers healthy and productive.

\section{Conclusions}

This study reveals that workers have good physical activity perception and the majority $(70 \%)$ of workers attain moderate level of physical activities based of WHO GRPAR and still a large number $30 \%$ of worker are physically inactive. Factors like place for physical activity, Being overload by office work, lack of awareness about physical activities, distance from gyms, safeness of roadside places, lack of communication with trainers and loss of interest in physical activity and ability to time management were considered as factors that can be reason for worker not to do physical exercise gyms or other places. Not doing physical activities of the workers will result in low office work performance. The government should give attention on the physical activities of the workers facilitation so that the workers will be enough active at their office work.

\section{Strength and Weakness of the Study}

The strength of the study is that the data collected by indepth interview and original. Social desirability may be one of the problem that workers may over report their physical activities.

\section{Recommendations}

We recommend on most of what key informant said as a reason for not to engage into physical activities.

\subsection{Government}

Should facilitate and prepare places for physical exercise for workers and community by allocating budget for establishing gyms and green arean that are used for physical activities so that the worker can be healthy and alert and provide good service for communities.

Government should motivate trainers and hire trainer in each organization so that they can help worker to engage into physical activities.

Government should create awareness use of physical activities in its structure and help workers to engage to physical activities.

\subsection{Workers}

Should be programmed not touch their wok time to participate in physical exercise.

Should not look only for comfortable places; they can do $\mathrm{PA}$ in any places even in their office by making body movement and stretch.

Should make physical activities as a part of their life and keep their health.

Should be out of bad attitude of PA trainers and understand that physical activities can help keep healthy and engage in to PA do not expend your time in different social media. Instead, use different videos that help you to do physical activities in your home.

\subsection{Researchers}

Further investigation is very important to find out problems that makes the worker not to go to PE place.

\subsection{Policy Makers}

Understand the benefits of PA regarding to the health of workers and try to design the policies that may contribute to health of office work which may have effect on public service.

$\begin{array}{ll}\text { Abbreviation/Acronyms } \\ \text { BSc } & \text { Bachelor of Science } \\ \text { GPAQ } & \text { Global Physical Activity Questionnaires } \\ \text { GRPAR } & \text { Global Recommended Physical Activity Rate } \\ \text { IPAQ } & \text { International Physical Activity Questionnaires } \\ \text { KI } & \text { Key Informant } \\ \text { MET } & \text { Metabolic Equivalents } \\ \text { PA } & \text { Physical Activity } \\ \text { PE } & \text { Physical Exercise } \\ \text { RPA } & \text { Regular Physical Activity } \\ \text { SD } & \text { Standard Deviation } \\ \text { US } & \text { United States } \\ \text { WHO } & \text { World Health Organization }\end{array}$

\section{Acknowledgements}

We want to thank Addis Ababa University College of 
Health Science IRB for reviewing and approving this research activity. Again, We want to acknowledge governmental offices like Adama town finance and economic cooperative office, Adama town municipal office, East shawa zone finance and economic cooperative office, and Adama town income and tax revenue office for allowing us to interview their workers at work office and finally, We want to thank all study participants.

\section{References}

[1] Harada N, et al., An evaluation of three selfreport physical activity instruments for older adults. Med Sci Sports Exerc, 2001. 33: p. 962-970.

[2] Salmon J., N. Owen, and A. Bauman, Leisure-Time, Occupational, and Household Physical Activity among Professional, Skilled and Less-Skilled Workers and Homemakers. Prev. Med. 30: 191-199, 2000. 30: p. 191-199.

[3] Gallagher NA, et al., Neighborhood factors relevant for walking in older, urban, African American adults. J Aging Phys Act., 2010. 18 (1): p. 99-115.

[4] U.S. Department of Health and Human Services, Physical activity and health; A Report of the Surgeon General. Atlanta, GA: U.S. Department of Health and Human Services, Centers for Disease Control and Prevention, National Center for Chronic Disease Prevention and Health Promotion. [online]. Available at: www.cdc.gov/nccdphp/sgr/pdf/chap5.pdf.1996.

[5] U.S. Department of Health and Human Services, Physical Activity and Health: A report of the Surgeon General. 1996, National Center for Chronic Disease Prevention and Health Promotion: Atlanta GCfDCaP.

[6] Maria Justine, A., et al., Barriers to participation in physical activity and exercise among middle-aged and elderly individuals. Singapore Med J 2013. 54 (10): p. 581-586.

[7] Maruí Weber Corseuil Giehl, et al., Physical activity and environment perception among older adults: a population study in Florianópolis, Brazil. Rev Saúde Pública, 2012. 46 (3): p. 1-9.

[8] Y. A. Tuakli-Wosornu, M. Rowan, and J. Gittelsohn,
Perceptions of Physical Activity, Activity Preferences And Health Among A Group Of Adult Women In Urban Ghana: A Pilot Study. Ghana Medical Journal, 2014. 48 1): p. 6.

[9] Melkamu Merid Mengesh, et al., Level of physical activity among urbanadults and the socio-demographiccorrelates: a population-basedcross-sectional study using the globalphysical activity questionnaire. BMC Public Health 2019. 19: p. 1160.

[10] Chalchisa Abdeta, Berhanu Seyoum, and Zelalem Teklemariam, Knowledge of the physical activity guidelines and factors associated with physical activity participation among adults in Harar town, eastern Ethiopia. BMJ Open Sport \& Exercise Medicine 2019. 5: 000463. doi: 10.1136/bmjsem-2018-000463.

[11] Jonine M Janceya, et al., Perceptions of physical activity by older adults: A qualitative study. Health Education Journal, 2009. 68 (3): p. 196-206.

[12] Annsofie Mahrs Träff, Elisabet Cedersund, and Catharina Nord, Perceptions of physical activity among elderly residents and professionals in assisted living facilities European Review of Aging and Physical Activity, 2017. 14: p. 2.

[13] Hallal PC, et al., Physical inactivity: prevalence and associated variables in Brazilian adults. Med Sci Sports Exerc., 2003. 35 (11): p. 1894-900.

[14] Reis et al., Prevalence and Variables Associated with Physical Inactivity in Individuals with High and Low Socioeconomic Status. Arq Bras Cardiol 2009. 92 (3): p. 193-198.

[15] Medinaet al., Physical inactivity prevalence and trends among Mexican adults: results from the National Health and Nutrition Survey (ENSANUT) 2006 and 2012. BMC Public Health, 2013. 13: 1063 http://www.biomedcentral.com/1471-2458/13/1063.

[16] Neha P. Gothe and Bradley J. Kendall, Barriers, Motivations, and Preferences for Physical Activity Among Female African American Older Adults. Gerontology \& Geriatric Medicine, 2016. 2: p. 1-8.

[17] Redhwan Ahmed Al-Naggar and Muhamed T. Osman, Perception towards Physical Exercise among University Students in Malaysia: A Medico-social Problem. Indian Journal of Applied Research, 2013. 3 (7): p. 474-475. 